Journal of mathematics and computer science $\quad 9$ (2014), 123-132

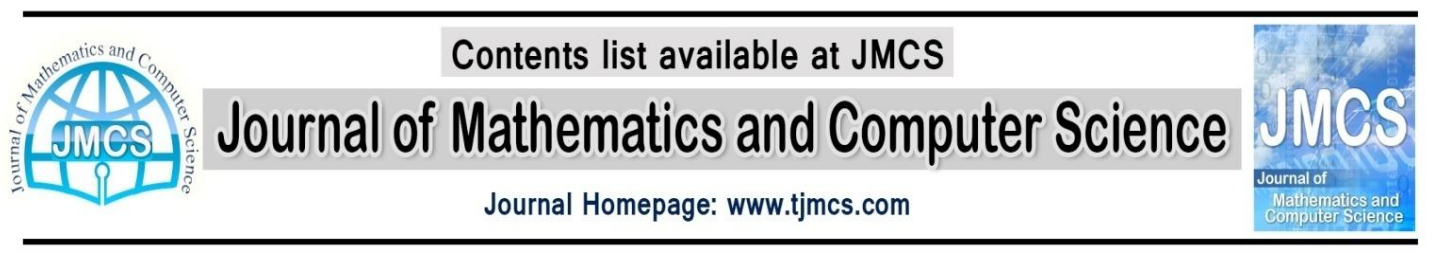

\title{
Relation of CIO Roles, IT and Business Alignment, and Organizational Performance
}

\author{
Saeed Ayat \\ Department of Computer Engineering \\ and Information Technology, Payame \\ Noor University, IRAN \\ Email:dr.ayat@pnu.ac.ir
}

\author{
Sodeif Farajkhah \\ Department of Information and \\ Communication Technology, Technical \\ and Vocational University, IRAN \\ Email:farajkhah@tvu.ac.ir
}

Article history:

Received August 2013

Accepted November 2013

Available online November 2013

\begin{abstract}
The ability to achieve business goals through IT is an important factor for the performance of organizations. One factor which affects the return of investment (ROI) in IT is strategic alignment of business and IT. Purpose of this study is to identify factors that affect the alignment of IT and business in the Iranian organizations. In this study the role and responsibilities of chief information officers (CIO) and their performance relationships with IT and business alignment and improvement of organizational performance are evaluated in the Iranian organizations. 80 IT professionals and managers from different Iranian organizations, who are identified by the State Scientific Research and Policy Center, responded to questions of this research through a website. Obtained results indicated that direct report to the chief executive by $\mathrm{CIO}$ and $\mathrm{CIO}$ membership in the executive committee improves IT services of the business. Findings show that the CIO has a key role in the alignment of business and IT. Limitations and problems of IT are properly understood by the CIO, therefore they can help to prepare appropriate IT and business strategies and consequently improve the performance of organizations.
\end{abstract}

Keywords: Business alignment, CIO role, competitive advantage, strategic planning, ROI.

\section{Introduction}

Using IT to create value for business is one of the most important questions for IT management. This question is important due to the growing importance of IT for 
communities, organizations and individuals [1]. New information technologies and systems including support systems, knowledge sharing systems, expert systems and human resource planning systems have provided many opportunities for organizations to create, acquire, store, disseminate and apply knowledge. Although many of these systems are found in organizations, many doubts exist about the effectiveness and efficiency of these systems [2]. On the other hand ICT acts as business enabler as well as business support.

The ability to use IT creatively and discover, implement or provide reliable services and IT risks with measurable criteria has created significant value for organizations [1]. Therefore the ability to achieve business goals through IT is an important factor for the performance of organizations. Based on obtained results of opinions of business managers, IT managers and researchers it is clear that factors such as the ability of IT managers, support of IT activities by senior management, cooperation of IT managers in strategic planning and integrated strategic planning of IT are the most important factors in determining the readiness of organizations for the strategic alignment of IT and business [3].

\section{Research problem}

Alignment of IT and organizational goals is an important factor in gaining competitive advantage, and also for the organizational survival. Therefore more strategic development of IT in organization is required to gain sustainable competitive advantages against other competitors. Based on duties of a chief information officer (CIO) in the organization, the $\mathrm{CIO}$ is responsible for creating alignment and achieving competitive advantage through IT for the benefits of organization [4].

The need for business and IT alignment has been generally accepted. But what does it mean in practical cases? And how does it appear in operational management? This study will focus on the relationship between business and IT strategies by using a strategic alignment model (SAM) proposed by Henderson and Venkatraman [5]. Will the CIO begin business strategy from IT and offer limited feedback to business strategy? Or should IT strategy be actively used as an input to business strategy? Is it important for the relationship between IT and business to be interactive or bilateral? SAM model defines the relationship between business and IT strategy and emphasizes the interactive relationship between two strategies. The model shows bilateral strategy alignment between business and IT strategies. The model also shows bilateral relations between the business strategy, IT strategy, organizational structure, processes, skills and IT architecture.

\subsection{Significance of the study}

Researches over the past three decades have not provided a good image of the return of investment in IT [6]. IT and business strategies, alignment of these two strategies, and CIO features in the recent yearshave been discussed as major factors in the return of investment in IT and organizational performance. But the role of CIO and its relationship with IT and business strategy alignment in the Iranian organizations has not been explored.

\subsection{Research objectives}

The main objective of this study is to identify factors affecting the alignment of business and IT strategies in the Iranian organizations. 


\subsection{3. Research questions}

A. What are the factors affecting the IT and business alignment in Iranian organizations?

$B$. What is CIO role in the IT and business strategy alignment?

4. Research hypotheses

A. Membership of CIO in executive committee has positive effect on business and IT alignment.

$B$. Direct report to CEO by CIO has positive effect on business and IT alignment.

C. CIO facilitates the business and IT alignment.

\section{Research methodology}

This research started with emphasizing on issues that affect the use of IT and CIO in the Iranian organizations. The concept of IT and business alignment and IT management pyramid are subjects that have been studied in order to answer research questions. Data were collected via an online questionnaire from IT experts. The experimental data were analyzed in order to identify the causes of the different views towards the CIO roles in business and IT strategy alignment planning and implementation.

1. Statistical population and sample size

The population consists of IT experts who havebeen identified by the science policy center in the field of IT. A total number of 80 IT experts responded the questionnaires.

\section{Research background}

Literature review is divided into two topics both of which affect the role of CIO and the relation of ICT with business strategic planning and implementation. The first issue is the growing role of IT in organizations and organizational processes.

Today traditional and embedded technology support total business processes and create its value. Therefore we should expect that changes in the role of IT influence the status of CIOs and IT that are closely related to the business strategy [7].The second issue deals with particular concepts of business and IT alignment and the frameworks related to these alignments. Business and IT alignment frameworks offer a theoretical motivation for changing role of CIO and it's relation with IT and business strategy alignment.

For many years alignment of business and IT has been a puzzle and challenge for organizations. Alignment of business and information technology can be considered as activities and organizational structures that show how the coordination of business and IT, setting of IT goals, defining the principal of organizing of IT activities, use of resources, risk management, governance structure and performance are evaluated [8]. Although business and IT alignment and IT governance have been the most important issues in the mind of IT managers for many years, we are still no closer to business and IT alignment today than we were 20 years ago. The need for senior business management with IT education is inevitable [9].

Business and IT alignment as well as alignment of IT with business priorities strategies have common solutions from the perspective of strategic planning. The key question is whether the IT investment is in line with corporate strategic goals? And therefore is it able to create value for business? Alignment is never complete rather it is a permanent process. Not only processes of alignment and business organizations are involved in current IT and business operations, but also they will affect IT and business future activities. IT strategy shows how IT tends to be used to support the business requirements. When the information is considered to be strategic, it can provide opportunities for enterprises to add value to 
products and services, contributes to competitive advantage containing costs and improves productivity and effectiveness of management to provide effective management [9].

In modern organizations almost all operational issues have a concept of IT. CIOs in their real sense are located at the crossroads of business strategy and IT operations. Therefore according to Prahaland [10], CIOs have the potential to facilitate the transfer of the business strategy to operational excellence.

The main framework for business and IT alignment is the strategic alignment model (SAM) provided by Henderson and Venkatraman [5]. This model attempts to give meaning and direction to business and IT strategic alignment. They argue that the inability to recognize the value of investments on IT is due to the lack of alignment between business and IT strategies in the organization. Business and IT strategic alignment are not an event but they are a process of continuous and changing compliance. There is no specific information to provide a sustainable competitive advantage. No technical information is stable rather its advantages come from ability of investment and take advantage of features offered by the IT.

Four areas of strategic options are defined in SAM model (Figure1):

1. Business strategy

2. IT strategy

3. Organizational infrastructure and processes

4. IT infrastructure and processes.

Logic of this model has been defined with two alignments: strategic fit which describes the relationship between internal and external domains of the SAM model and integration function which describes the integration function between business and IT domains.

The position in the IT marketplace involves three sets of choices:

1. IT scope

2. IT systems competencies

3. And IT governance (which could be understood as IT decision making rights).

Similarly the scope of internal information systems (IS) has three parts (type):

1. Information system architecture

2. Information system processes

3. And information systems skills

Inadequate fitness between the inner domain and outer domains of IT is major reason to fail obtain benefits of IT investments. Thus strategic alignment model is used to emphasize the need to integrate IT and business strategies. The model defines two types of integration: strategic integrity and operational integrity. Strategic integration describes capabilities of IT in designing and supporting business strategy. Operational integration deals with enterprise infrastructure, process integration, information system infrastructure and process. Strategic alignment model requires a fundamental change in the orientation of the internal IT focus on foreign market areas of IT which is defined by the expected level of IT skills and IT governance. Future challenges in the use of IT will lie in the proper perspectives of alignment that is in charge of best fitting of the specific business situations and goals of the organization. SAM model emphasizes the diversity of roles performed by the line and CIOs. 


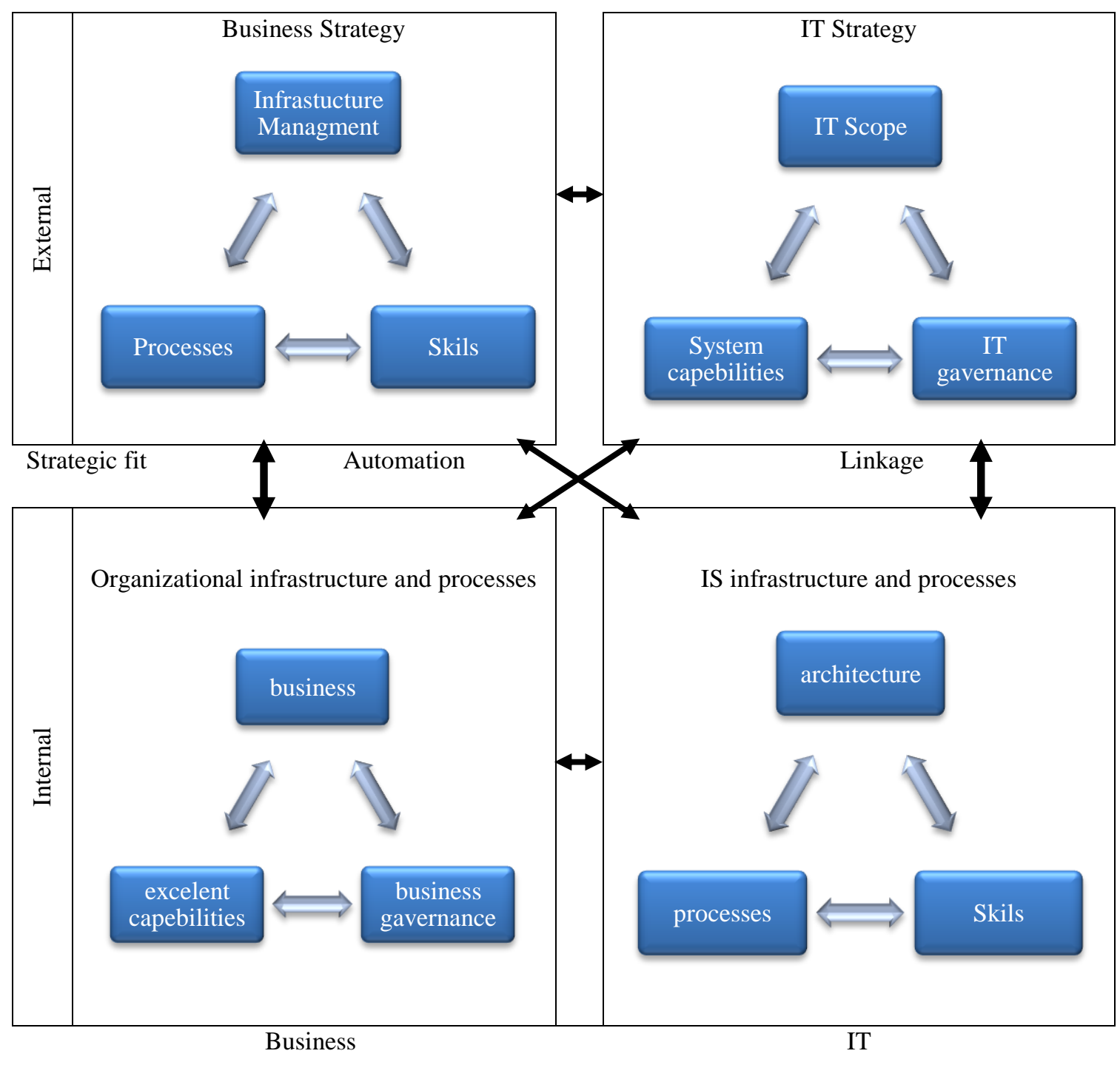

Functional integration

Figure 1-the Strategic Alignment Model (Henderson and Venkatraman)

\section{Findings}

\subsection{IT strategy as a part of business strategy}

Findings of this study indicate that decisions about IT strategy are adopted by the executive committee or a group of business leaders. In some organizations CIO or the board will make decisions about IT strategy. In many organizations CIO manages IT strategy process and also approval of IT strategy more or less has a procedural aspect. However, many CIOs lack communication and interaction between business management and IT. CIO or board is mainly responsible for IT related decisions, IT infrastructure and its architecture. Moreover, other routine decision procedures and decision-making 
structures such as special projects and decisions across the business units are used by them.

Most common answer to the question of the role of IT in planning and executing organizational strategy was that IT does not play any role in this case. In most cases IT strategy begins by accepting business strategy as its starting point.

Figure 2 shows weaknesses among current business strategy and IT action plan regarding these interviewees. There is no alignment between the two strategies. IT strategy is improved and executed after business strategy. Therefore there is no feedback from IT to the business. When business strategy sets the direction without any interaction with IT requirements, the enabling role of IT is completely missed.

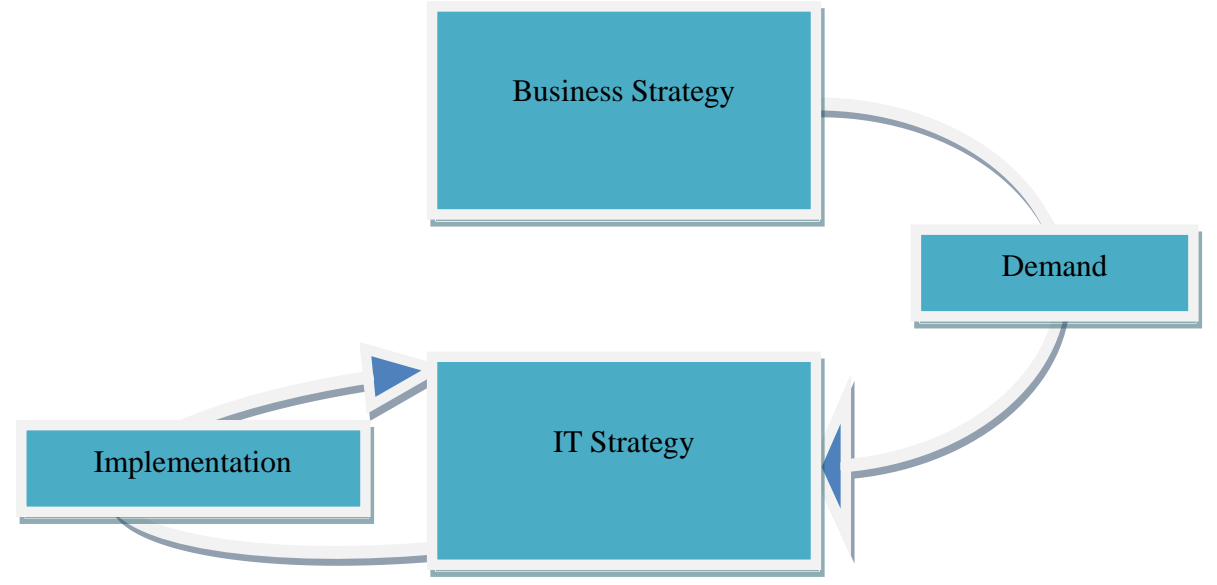

Figure 2: Lost interaction between business strategy and IT strategy

When issue of the importance of IT in business rises, the link between business and IT strategies should be interactive. Business strategy should provide some directions for IT. The possibilities and limitations of IT should be considered by the business strategy. Interactive planning, organizing and implementing of IT and business strategies are the effective ways to ensure maximum business added value. Figure 3 shows the two links.

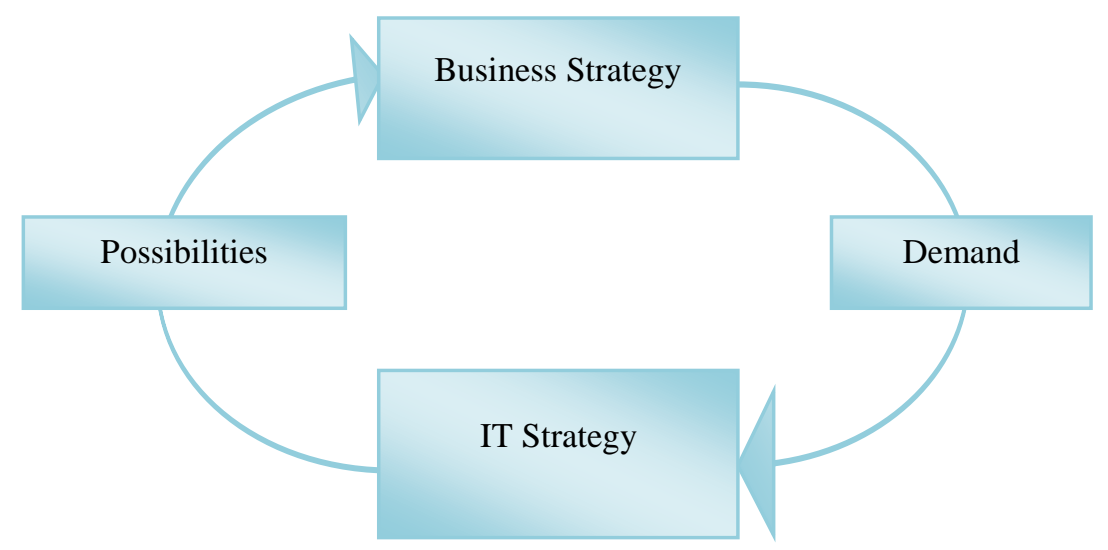

Figure 3: IT strategy linked to business strategy.

According to given answers it seems that organizations have found that IT on an operational level has a significant impact on business performance. According to interviewees it is obvious that they think all institutions' operations will be halted by IT 
failure. Again only a few companies have understood strategic business and IT alignment and much efforts are made to establish links between IT and business strategies. These companies were either too dependent on IT, or CEO (and other senior managers) had understood and defined the value of IT for business. Moreover it seems that the visionary and active CIO led to a strong influence on the strategic level in alignment. In summary most interviewees did not care or did not understand how to examine the alignment of business and IT strategies. It is not surprising that the biggest concern for many of the interviewees was that IT was not sufficiently involved in strategic planning of businesses nor did not have access to them. In these companies IT operations are seen only from a narrow perspective so that business needs are directed towards IT. A response is received from the other end of the spectrum with the notion that it is hard to separate IT strategy from business strategy due to the strong tie established between them.

Figure 4 clearly shows the problem of alignment between business and IT strategy planning based on the results of this study. The arrows show the impact of each factor. Business strategy approximately sets one-way for the IT strategy and different processes. The problem shown in Figure 4, in addition to the lack of interaction between business and IT strategies, is that business strategy is set regardless of their organizational skills, capabilities and limitations. This finding is very important because modern methods offer resource-based view of strategy while the strategic advantage is the strengths of the organization. In fact the interaction between business strategy, IT strategy and various processes of organization are vague or nonexistent. Senior managers in most organizations define the business strategies in isolation without considering the limitations of IT and facilities. IT, organizational skills and competencies in strategic planning is considered. As it can be seen from the arrow size, other factors also have no significant influence on business strategy. This is another sign of the presence of alignment gaps in planning and executing business strategy. However, some of the arrows represent the balance in the interaction.

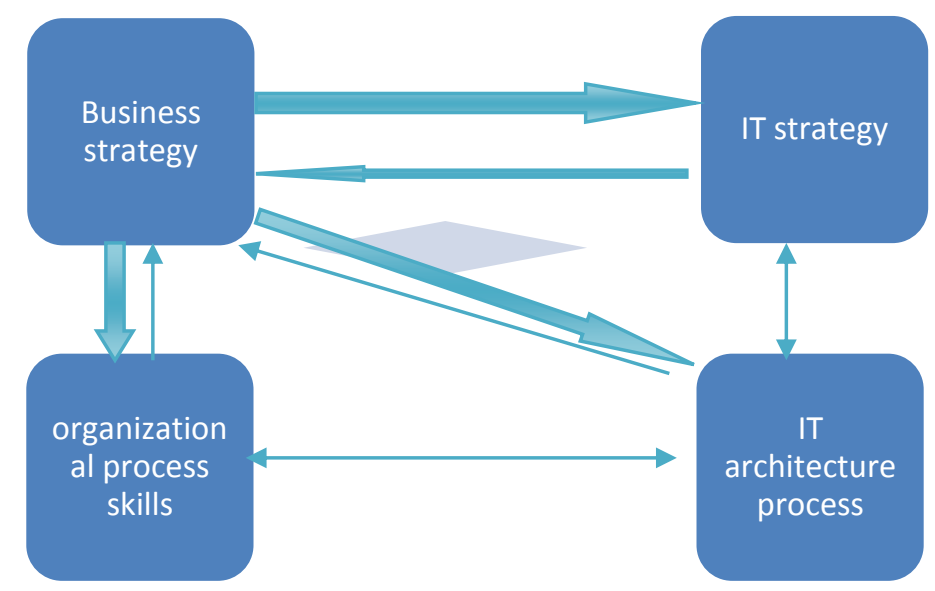

Figure 4: Strategic Alignment, based on the results of interviews

Figure 5 focuses on two areas of IT management which is extracted from the comments of interviewees. The area in the vertical oval shape shows how majority of those who are interviewed have employed business and IT alignment issue in the centerpiece of their approach. Their understanding of IT is more than their understanding about operations and their focus is on the relationship between IT strategy and IT processes. Most of them are concerned with the costs of operation and productivity of IT. Very high performance and 
reliability is expected from IT but it may be invisible. Even there is implicit or explicit objective for minimizing the amount of IT costs. In these organizations IT and IT management issues have low or medium priority in the agenda of senior management.

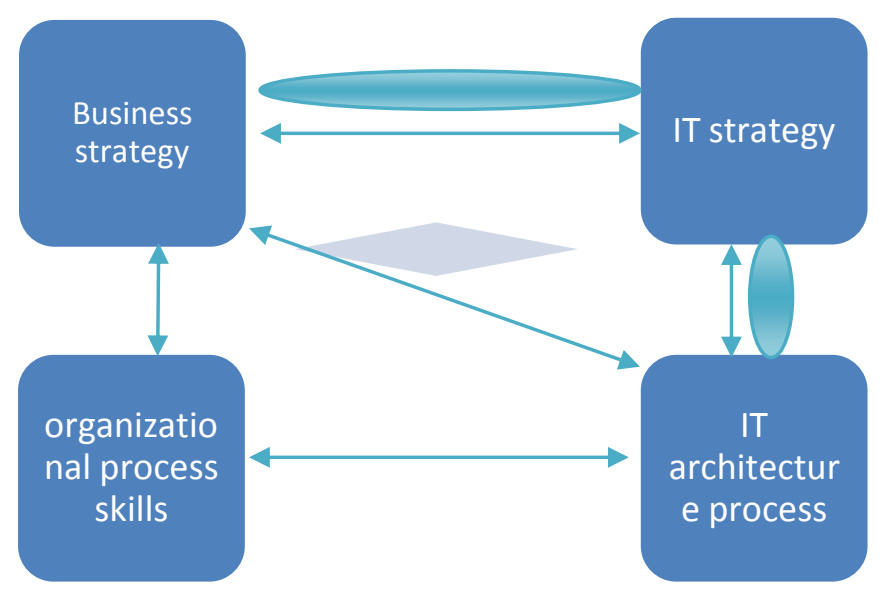

Figure 5: The alignment of the results of interviews

The area $\bigcirc$ in Figure 5 describes the alignment of business and IT in the company which views IT from a strategic perspective. Reliability and costs productivity of IT are still required. The value expectation of these types of companies from IT is high and ambitious. They try to communicate their business and IT in order to establish better links with IT implementation and development of their business and also try to activate enabler plans.

These are some characteristics of such companies:

1. They are completely dependent on IT in their business and have a long history of using IT.

2. They have an ideal CEO and executive committees that are able to deploy IT actively.

3. They have an experienced, innovative and business-oriented CIO who is able both to provide the strategy and execute this type of vision.

\subsection{The Role of IT in business strategy}

The need for business and IT alignment is generally accepted. Results of this study confirmed the alignment of business and IT topics that were emphasized by almost all interviewees. To clarify this issue we asked if the IT performance and CIO should be considered from business strategy as starting point for IT strategies with limited feedback to the business strategy or should the IT strategy provide input to business strategy? In addition we asked whether the relationship between business and IT should be an one way relationship (IT should have the supporting role) or an interactive relationship (IT should have the supporting and the enabler roles). The institutions, that defined their business role of IT while IT managers were business managers too, had been created more or less sophisticated mechanisms for business and IT alignment. In these companies the IT strategy with business strategy process were unified.

It may be asked what the role of CIO is in business and IT strategies alignment? This role is illustrated in Figure 6. Figure 6 shows the cycle of interactive business and IT alignment, the development of IT and services, performance management report, IT risks, and value creation for business by using IT. Generally IT managers usually need to be 
facilitators of these processes.

Based on these results it has been a significant issue for many corporations to have skills in order to achieve better alignment of business and IT. Understanding the strategic role of IT by CEOs, rate of industry dependent on IT, long history of IT and personal competencies of CIO appear as key factors for business and IT alignment development.

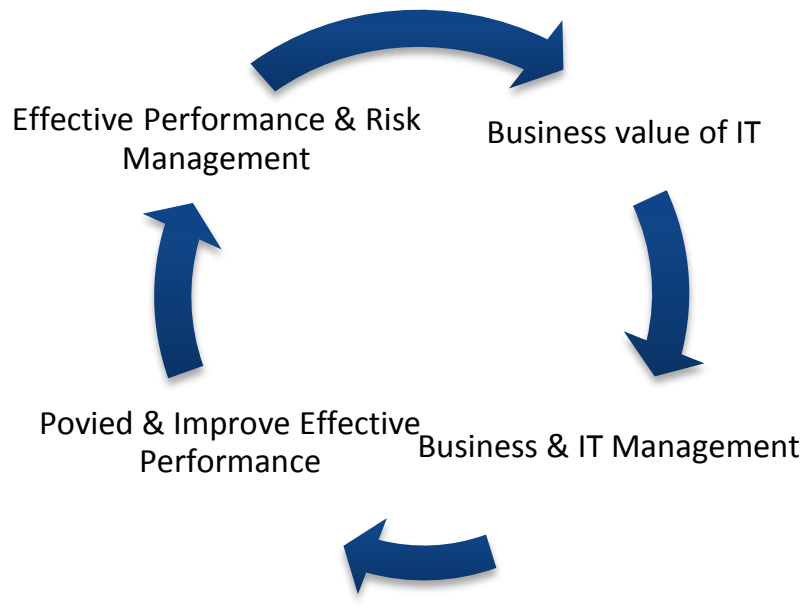

Figure 6: The Role of CIO in Strategic IT and Business Alignment

\section{Conclusion}

The strategic alignment of business and IT is an endless process of evolving the need to try and support the business and IT managers. The importance of IT for business has a great role in the alignment of business and IT operations in order to create value and manage IT roles. The results of this study showed that CIOs play a major role in the business and IT alignment which suggests that IT managers should have strong positions in their organization to be able to fulfill the task perhaps as members of the executive committee.

Managers planning and implementation of corporate strategy, from the perspective of senior IT , are more crucial than having such a position without any authority. It is not required that $\mathrm{CIO}$ to be a formal member of the executive committee if $\mathrm{CIO}$ has the ongoing access to IT and business strategies and also if it has an active role in this process. Enabling IT managers to make strategic decisions will increase delivering of the business value for IT usage.

In order to gain more value of using IT, it is required that an enterprise establish a close and interactive relationship between business and IT strategy processes. IT strategy, as a part of standard processes to evaluate the overall strategy of mutual engagement, is one of the simplest organizing tools.

The final recommendation is that organizations should perform more actions in line with business and IT strategies alignment. Often the only communication is between business and IT, but planning constraints and opportunities of IT in business processes should be considered in advance.

\section{Suggestions for future research}


In this study factors affecting business and IT alignment strategies and their impact on organizational performance were studied. Most organizations understand the importance of alignment, but there are no instructions about how to implement processes. Therefore different methods for implementing strategic alignment between business and IT in the organizations are among the topics that can be explored. Another field of research can investigate the relationship between managers' background with field of organization's activities alignment.

\section{Acknowledgment}

This research is supported by a research grant from Payame Noor University.

\section{References}

[1] S. Farajkhah and S. Ayat, "Identifying and prioritizing the factors affecting the role of chief information officer in the current and future business," proc. CISIS'11, 2011, pp.329-332

[2] M. Mehrizizadeh, The role of ICT in knowledge management, Sharif University of Technology, master's thesis, 2005.

[3] A. Arabscorch, Providing a model for assessing organizational readiness for strategic IT and business alignment, master's thesis, Tehran University of Technology Management, 2005.

[4] M. Khaki, Provide a model for assessing organizational readiness to conduct successful strategic planning of information systems and information technology, master's thesis, Tehran University of Technology Management, 2004.

[5] J. C. Henderson and N. Venkatraman, "Strategic alignment, Leveraging information technology for transforming organizations," IBM Systems Journal, vol. 38, no. 1, Nov. 1999, pp.472-484.

[6] S. Ayat, D. Karimzadegan and S. Farajkhah, "Presenting a framework to identify factors affecting the performance of information technology in organizations," the first regional conference on new approaches in computer engineering and information technology, Iran, 2011.

[7] M. G. Sobol and G. Klein, "Relation of CIO background, IT infrastructure, and economic performance," Information \& Management Journal, vol. 46, no.1, Sep. 2009, pp. 271-278.

[8] D. Tami and K. Hannu, "An Integrated Framework for IT Governance and the Development and Validation of an Assessment Instrument,” Proc. HICSS'06, IEEE, 2006, p. 203.

[9] IT Governance institute (ITGI), Board briefing on IT Governance, www.itgi.org, 2003

[10] C. K. Prahaland, "CIOs Hold Key to Operational Excellence” Optimize, 5:5, 2006, p. 66. 